namely, to take care that the tube is passed well into the uterus before any of the fluid is injected; otherwise the vagina will be corrugated and the os uteri contracted from the effects of the iron, the styptic will not reach the interior of the uterus, and great difficulty will be experienced in any subsequent efforts to introduce the tube. The same reason, namely, the effect produced by the action of the styptic on the vagina and os uteri, renders the application of the iron by means of a sponge difficult and unsatisfactory.

In conclusion, I believe the injection of the perchloride of iron to be not only a justifiable, but, in general, a safe mode of treating severe cases of post fartum hæmorrhage, and that it, or the use of some similar styptic, can alone be relied on in severe cases.

The great injury to which steel instruments are liable, when kept in a bag which also contains a solution of the perchloride of iron, has in. duced me to carry the salt in the solid form, the bottle containing it being enclosed in a box-wood case.

\section{ON THE REMITTENT FEVER OF THE WEST COAST OF AFRICA.}

\section{BY JOHN M. HUNTER, M.D., Staff-Surgeon, R.N.}

IN answer to a request that medical officers who have had experience of fever on the African coast would forward the results of their observa. tions, I beg to send some notes, made in the course of four years' service in various men-of-war, during which period nearly every port from Sierra Leone to Benguela was frequently visited.

The majority of cases of fever seen on board vessels that cruise along the coast are cases of simple continued fever, resulting from the effects of the sun or over-fatigue, or from careless exposure to chills at night. The attack commences with rigors, frontal headache, hot skin, coated tongue, and can only be diagnosed from remittent fever by the progress of the case, or, as I believe, by the temperature of the skin, as shown by the thermometer immediately on the hot stage supervening. The temperature then is always under IO2 deg., generally under IOI deg.; and with a saline aperient and a few doses of quinine, the febrile symptoms disappear in from twenty-four hours to three days; strength is rapidly regained, and usually the period on the "sick list" is from three to eight days. But if the vessel anchor near the mouth of a river, or herself or boats go up it, or if any of her crew sleep ashore in a malarious district, being unprotected by quinine, a very different disease is developed. The initiatory symptoms were much the same as in the simple continued, only generally of a severer character. There was a general feeling of malaise for several days; then (often in the evening) chilliness, rigors, severe frontal headache, and vomiting; the skin became dry and hot, the tongue was coated with whitish.brown fur, and the bowels were usually constipated. Occasionally diarrhœa existed ; but this appeared to have no beneficial effect on the severity of the symptoms. The pulse was full and bounding, from 1 Io to 120 ; sometimes though rapid, it was not full. The temperature in the axilla was from 103 to $105.8 \mathrm{deg}$. So confident did I become in the indications of the temperature, as shown by the thermometer, that, when the temperature at the outset was under $102 \mathrm{deg}$., I felt certain I had to deal with only a case of febricula, that would be well in a few days; and, on the other hand, when the temperature was over 103 deg., I knew that I had met with a case that would present serious symptoms and have a slow convalescence. The febrile condition generally continued for a period of from four to fourteen days, or even longer-remissions usually occurring in the morning, and in some cases being more marked every second day. In a few cases only have I seen the head-symptoms so serious as to appear likely to be the cause of death. In all the others, the excessive irritability of stomach which caused all food and drink to be rejected immediately it was swallowed, the great exhaustion from this, and the wealiness arising from the continuance of the febrile condition, occasioned the fear that death would result from failure of the heart's action during some slight exertion-the most usual manner of death in cases which terminate fatally.

I did not use the thermometer till the year 1870 ; but I used it twice a day, at 9 A.M. and 5 P.M., in every case that showed febrile symptoms, and I here give four tables, which are from fairly typical cases. No. I was a case of simple continued fever, convalescent on the fifth day. No. 2 was a case of remittent, showing the second day remizsions ; on the fourteenth day, when the fever subsided, the patient was as helpless as an infant. No. 3 was a case of remittent, complicated with dysentery. At one time recovery appeared hopeless in this case : beef-tea increased the dysentery, and Liebig's extract and wine were the only foods used. No. 4 was a case where the fever had a short course, but the resulting feebleness was considerable and long continued; and during the first week the pulse had the peculiar jerky hardness which I have found to be a sign that a very little exposure or fatigue will cause a relapse. I have no fatal case to record out of a considerable number, though many were so shattered in health as to necessitate their being sent to England. The naval statistics of the West Coast of Africa for the year 1870 show that the deaths from continued and remittent fever were only . 6 per cent. of the cases-a result, no doubt, greatly due to being able to remove bad cases quickly from the focus of the disease, but still a result which is very encouraging.

$$
\begin{aligned}
& \text { Tables of Temperature in Simple Continued and Remittent Fever. } \\
& \text { TAble I. } \\
& \begin{array}{crrrrr} 
& \multicolumn{3}{c}{\text { Temperature. }} & \multicolumn{3}{c}{\text { Pulse. }} \\
\text { Days. } & \text { M. } & \text { E. } & & \text { M. } & \text { E. } \\
\text { I. } & - & \text { roo. } & \ldots . & - & 94 \\
\text { 2. } & \mathbf{1 0 0 . 8} & 98.5 & \ldots . & 95 & 95 \\
\text { 3. } & 98.5 & 97.3 & \ldots . & \mathbf{1 0 0} & 82 \\
\text { 4. } & 97.3 & 97.3 & \ldots . & 72 & 76 \\
5 . & 98.2 & 98.3 & \ldots . & 76 & -
\end{array} \\
& \text { TABLE II. } \\
& \text { TABLe III. } \\
& \begin{array}{c}
\text { Temperature. } \\
\text { Pulse. } \\
\text { M. E. }
\end{array} \\
& \begin{array}{rrrrr}
103.2 & 99.5 & \ldots . . \overline{8} & 82 \\
103.4 & \ldots .8 & 82 & 82
\end{array} \\
& \begin{array}{llllll}
99.8 & 102.8 & \ldots & 78 & 78 & 78
\end{array}
\end{aligned}
$$

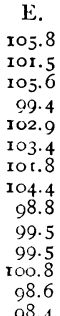

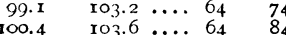

$$
\begin{aligned}
& \begin{array}{llllll}
99.4 & \text { 10I. } 6 & \ldots . & 66 & 66 & 78
\end{array}
\end{aligned}
$$

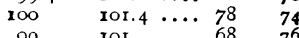

$$
\begin{aligned}
& \begin{array}{llllll}
99 & \text { ror } & \ldots & 68 & 68 & 76 \\
97.8 & 99.8 & \ldots & 68 & 72
\end{array} \\
& \begin{array}{lllll}
97.8 & 99.8 & \ldots & 68 & 72 \\
98.8 & 97.9 & \ldots . & 72 & 50 \\
97.2 & 97.2 & \ldots & 68 & 62
\end{array} \\
& 97.2 \quad 97.2 \ldots .68 \\
& 97.2 \ldots .6268 \\
& \begin{array}{llll}
98.4 & \ldots . & 62 & 64 \\
08.2 & \ldots . & 62 & 62
\end{array} \\
& \text { TABLE IV. } \\
& \begin{array}{crr} 
& \multicolumn{2}{c}{\text { Temperature. }} \\
\text { Days. } & \multicolumn{1}{c}{\text { 1I. }} & \text { E. } \\
\text { I. } & -\overline{105.4} & \text { 105.4 } \\
2 . & 98.8 & 97.4 \\
3 . & 100.4 & 102.3 \\
4 . & 100.4 & 98.4 \\
5 . & 96.6 & 96.4 \\
6 . & 97.4 & 97.2 \\
7 . & 98.4 & 98.4
\end{array}
\end{aligned}
$$

\begin{tabular}{ccr} 
& \multicolumn{2}{c}{ Temperature. } \\
Days. & \multicolumn{1}{c}{ M. } & \multicolumn{1}{c}{ E. } \\
I. & - & 105.8 \\
2. & 101.8 & 101.5 \\
3. & 103.5 & 105.6 \\
4. & 100.4 & 99.4 \\
5. & 102.7 & 102.9 \\
6. & 100.6 & 103.4 \\
7. & 103.5 & 100.8 \\
8. & 102.6 & 104.4 \\
9. & 101.5 & 98.8 \\
10. & 103.4 & 99.5 \\
11. & $\mathbf{1 0 1 . 6}$ & 99.5 \\
12. & 98.4 & 100.8 \\
13. & 98.4 & 98.6 \\
14. & 98.4 & 98.4
\end{tabular}

Remittent fever is non-contagious, and the period of incubation generally varies from three to twelve days. The treatment pursued was much the same by all the medical officers of the squadron, varying a little as regards large and infrequent, or small and frequent, doses of quinine. It is scarcely necessary to mention that no one used blood-letting; the rapidly supervening prostration due to the effects of the fever itself, and the dire results of its use in former times, were sufficient to prevent this. The Portuguese doctors usually give an emetic at the commencement, but uncontrollable irritability of stomach is apt to follow this. I pursued the following course. The patient was placed in a cot on the upper deck, or in a well ventilated part of the ship, and told to exert himself as little as possible. His hair was cut off, and single strips of calico, dipped in vinegar and water, were applied over the fore part of the head; a grass-mat pillow helped to keep the head cool, and always gave much relief to the severe headache. If there were any vomiting, thirty minims of chlorodyne were given, and a mustard plaster applied over the stomach. As soon as the vomiting ceased, quinine, in four.grain doses, was given every four hours in the following form.

$\mathrm{R}_{x}$ Quinæ sulph. gra. iv; acidi citrici gra. iv ; magnesiæ sulphatis gra. $x$; syrupi aurantii $3 \mathrm{ss}$; aquæ $\zeta j$; fiat haustus quartâ quâque horâ sumendus.

In about twelve hours the bowels usually were opened; if not, about three drachms of sulphate of magnesia were given in the form of draught, and, if necessary, an enema also was used. If there were diarrhœa, the sulphate of magnesia was omitted from the mixture; and if vomiting ensued, about fifteen minims of chlorodyne or compound tincture of chloroform were given, which generally succeeded in stopping it. In one case, the vomiting was so persistent that I had to inject one-third of a grain of muriate of morphia subcutaneously, which had the desired effect ; and the patient's skin, which had become yellow, resumed its natural colour in twenty-four hours. Cool champagne in small quantities was also found useful in allaying the stomachic irritability. The underclothing was frequently changed, and an occasional sponge-bath of tepid water, tinged with permanganate of potass, was found to be very refreshing. One of the most important points was the dieting of the patients. Stimulants were well borne, and were found to be beneficial in quantities of about four ounces of brandy, or six to eight ounces of port, or ten ounces of champagne, daily. Beef-tea (filtered through blotting-paper to remove the fat, if there were nausea), Liebig's extract, preserved chicken, milk, and eggs beaten up, were given frequently and in small quantities. The desire for food was gone, and in many cases the difficulty of retaining nourishment was the chief element of danger in the case. 
The patient was strictly forbidden to sit up during the later stages of the disease, as many cases have been lost through neglect of this rule, even when the actual fever had left the patient. Convalescence was often very tedious, and in one case complicated with sunstroke. Paralysis of the lower limbs remained for so long as two years, and in another dementia supervened. In two cases, where carbonate of ammonia was used as a stimulant, a typhoid condition came on, and departed when the use of the drug was given up.

As regards prevention, I have many reasons for placing great confidence in the daily use of the quinine. On one occasion, a boat's crew went up the river Congo as far as Embomma, a distance of fifty miles. Each person took four grains of quinine once and sometimes twice a day; and though they were nearly a week in the river, not one had fever. On another occasion, a boat's crew went up the same river as far as Ponta da Linha, a distance of thirty miles, and were absent about four days. Owing to the hurried manner in which, from pressing circumstances, the boat was sent away, no quinine was taken, and soon after their return two very severe cases of remittent fever appeared amongst the ten who formed the boat's crew. The barque Camilla, in 1868 , anchored in a part of the River Congo, called Banana Creek, and I was asked to visit her. The crew consisted of Englishmen and natives of the West Indies. They had not used any quinine, and every one was ill, excepting a little English boy, who afterwards told me that he had run away from school to join the ship. The first mate was dying and was quite insensible, and unable to swallow anything. The second mate had been constantly sick for three days, and was very weak, but quite collected and sensible, endeavouring to crawl about the ship and do the light duty required in port. I made up some quinine mixture, gave them chlorodyne, and also carbolic acid for the bilges, which were foul, and did all I could for them in one day. We left the place the same evening; but I afterwards heard that the second mate recovered; the first mate and another died, and one white seaman I afterwards saw at Thabenda in a condition of dementia, the result of remittent ferer.

\section{CLINICAL MEMORANDA.}

\section{FACAL ACCUMULATION.}

Mr. S., aged 6o, had been more or less ill for two years, with gradually increasing distension of the abdomen, accompanied by some emaciation, loss of appetite, much flatus, and confined bowels. On examination, I detected an immense tumour filling the whole of the abdomen, except a small portion of the left lumbar region, where there was tympanitis. It passed upwards under the ribs, downwards into the pelvis, was perfectly smooth, very hard, and quite immovable; over a small part, to the right of the umbilicus, was indistinct resonance; and somewhat below this, I felt a coil of small intestine between the tumour and abdominal wall, evidently filled with fæcal matter. By firmly pressing the finger against the swelling, at different parts, I found that a slight indentation was made, though with difficulty. The superficial abdominal veins were much distended. The rectum was full of large hard lumps. My diagnosis was fæcal accumulation to an extent I never saw nor heard of before. Large injections of warm water daily for three weeks, aided by small doses of belladonna and nux vomica, brought away a most astonishing quantity of fæcal matter, and resulted in the total disappearance of the tumour, and the restoration of the patient to perfect health. I may add, that homoopathy had had a lengthened trial in this case.

Thomas Cole, M.D.Lond., M.R.C.P.

Physician to the Royal United Hospital, Bath.

\section{THERAPEUTIC MEMORANDA.}

\section{THE USE OF PHOSPHORUS.}

Mr. J. Ashburton Thompson is polite enough to say that some details of those cases in which I found phosphorus of no value would prove interesting to the members of the Association, and I would gladly comply with his request, if I had anything novel to remark upon the general aspect of these diseases. Such, however, is not my fortune; and hence a summary of the cases may, perhaps, be considered sufficient.

Locomotor Ataxy. - Dr. Thompson may quite fairly doubt my right to speak of the valuelessness of phosphorus in this affection, as a sufficient number of cases are not likely to fall beneath the care of any single surgeon. It so happened, however, that, some time ago, I was much interested in diseases of the spinal cord; many of my professional friends very kindly gave me opportunities of seeing, and in some instances treating, cases of their own. In this way, I obtained notes of eighteen cases of locomotor ataxy, in all of which, first, nitrate of silver and then phosphorus were tried, but none of them, in any case, seemed to derive the slightest benefit.

Melancholia. - I treated three cases with phosphorus. There was no amendment in any of them ; but one gentleman, a solicitor, of a highly nervous temperament, suffered, as a result of the treatment, from a severe and obstinate attack of dyspepsia.

Impotence.-During the last six months, two or three cases of impotence have presented themselves in the out-patient department of the Manchester Infirmary: to all of them I have administered phosphorus, but they have failed to derive any benefit from the drug.

Mercurial Tremor.-A very well-marked case of this disease presented itself among out-patients of the infirmary some months ago, who recovered under the use of iodide of potassium, after phosphorus had completely failed.

I should like, however, before closing this memorandum, to mention a disease which appears to be influenced in the most beneficial and rapid manner by the administration of phosphorus-I mean bronchocele. I have only notes of one case, but this is an instructive one. The patient, a girl aged 20, had an increasing goître for some months, when she was placed on the usual iodine treatment, with no benefit whatever. After a month's interval of no treatment, phosphorus was given in doses ranging from the one-fiftieth to the one-twentieth of a grain, with the effect of directly causing a diminution in the size of the gland ; the decrease went on steadily until the neck, in a month, measured two inches less than it did before the commencement of the treatment.

S. Messenger Bradley, Manchester.

\section{OBSTETRIC MEMORANDA.}

\section{ON THE ANTICIPATION OF POST PARTUM HAMORRHAGE.}

Dr. ATtrill does not state in his paper on this subject, which appeared in this JouRNAL of November Ist, that it is of the utmost importance that the binder should be placed round the patient, if possible, before the completion of the second stage of labour, so that it can be tightened up without moving her, as soon as the placenta is expelled. It used to be customary to wait till the third stage was completed, and then bind; but very early in my professional career, I discovered the danger of movement immediately after the expulsion of the placenta to place the binder under the patient, which was almost always followed by more or less relaxation of the uterus and hæmorrhage, slight or otherwise, even when pressure was kept up by the hand on the fundus. I invariably have the binder put on beforehand, so that it can be tightened up after everything is completed without any movement of the patient; and I have for many years had so much reason to be pleased with this precaution, that I should insist on it as one great safeguard against post partum hæmorrhage.

6, Seymour Street.

Percy Boulton, M.D.

\section{FORTNIGHTLY HÆMORRHAGE DURING PREGNANCY.*}

$H$. H., age 36 , states that in all her pregnancies there has been $a$ hæmorrhagic uterine discharge, more profuse than her menses (which are of usual quantity and quality), but of exactly the same nature, every fortnight up to the sixth month, whence, until labour, there has been no loss. Each flux is preceded by a few days' very severe headache, and is accompanied by much dorsal pain and very bad bearing-down sensations. She never has any leucorrhœea. When not pregnant, she has regular monthly catamenia; an abundant discharge every fortnight is therefore her test of pregnancy; this recurs fortnightly for four or five months after each labour; the menses then become natural. She has had seven children : all carried to full time, and born alive and perfect. When she was pregnant with her first, the hæmorrhage was so copious that her medical attendant told her the pregnancy could not go on. It was not more abundant then than it has always been since. Treatment, position, and rest, had no influence; so she now takes no extra precautions during her pregnancies. She does not lose much after her confinements, and there are no ordinary indications of hæmor. rhagic diathesis. She is a stout plethoric woman, who says she "makes blood" very quickly, and that her mother used to be often bled

\footnotetext{
* Read before the Worcester Medical Society.
} 